This item was submitted to Loughborough's Research Repository by the author.

Items in Figshare are protected by copyright, with all rights reserved, unless otherwise indicated.

\title{
The impact of a novel Structured Health Intervention for Truckers (SHIFT) on physical activity and cardio-metabolic risk factors
}

PLEASE CITE THE PUBLISHED VERSION

https://doi.org/10.1097/JOM.0000000000001128

\section{PUBLISHER}

Lippincott, Williams \& Wilkins

\section{VERSION}

AM (Accepted Manuscript)

\section{PUBLISHER STATEMENT}

This work is made available according to the conditions of the Creative Commons Attribution-NonCommercialNoDerivatives 4.0 International (CC BY-NC-ND 4.0) licence. Full details of this licence are available at: https://creativecommons.org/licenses/by-nc-nd/4.0/

\section{LICENCE}

CC BY-NC-ND 4.0

\section{REPOSITORY RECORD}

Varela-Mato, Veronica, Nick Caddick, James King, Vicki Johnson, Charlotte L. Edwardson, Thomas E. Yates, David Stensel, Heather Daly, Myra A. Nimmo, and Stacy Clemes. 2019. "The Impact of a Novel Structured Health Intervention for Truckers (SHIFT) on Physical Activity and Cardio-metabolic Risk Factors". figshare. https://hdl.handle.net/2134/26354. 
The impact of a novel Structured Health Intervention for Truckers (SHIFT) on physical activity and cardio-metabolic risk factors

Veronica Varela-Mato, $\mathrm{PhD}^{1,2}$, Nick Caddick, $\mathrm{PhD}^{3}$, James A King, $\mathrm{PhD}^{1,2}$, Vicki Johnson, Miss

${ }^{4}$, Charlotte Edwardson, PhD ${ }^{4,2}$, Thomas Yates, PhD ${ }^{2,4}$, David J Stensel, Prof ${ }^{1,2}$, Heather Daly, Prof ${ }^{4}$, Myra A Nimmo, Prof ${ }^{5}$ and Stacy A Clemes, PhD ${ }^{1,2}$.

\section{Author's affiliation}

1. School of Sport, Exercise and Health Sciences, Loughborough University, Loughborough, United Kingdom.

2. NIHR Leicester-Loughborough Diet, Lifestyle and Physical Activity Biomedical Research Centre, United Kingdom.

3. Veterans and Families Institute, Anglia Ruskin University, United Kingdom.

4. Leicester Diabetes Centre, Leicester General Hospital, University Hospitals of Leicester, UK

5. College of Life and Environmental Sciences, University of Birmingham, UK

Corresponding author contact details: Veronica Varela Mato. School of Sport, Exercise and Health Sciences, Loughborough University, Loughborough, United Kingdom.

Contact number: $+44(0) 1509228170$

Email: v.varela-mato@lboro.ac.uk 


\section{Disclaimer}

The authors wish to state that all drivers participating in this study were medically fit to drive and comply with the DVLA requirements.

The author(s) disclosed receipt of the following financial support for the research, authorship, and/ or publication of this article: The research was supported by the National Institute for Health Research (NIHR) Diet, Lifestyle \& Physical Activity Biomedical Research Unit based at University Hospitals of Leicester and Loughborough University. The views expressed are those of the authors and not necessarily those of the National Health Service (NHS), the NIHR or the Department of Health.

Funding no funding was received for the development of this study

\section{Competing interests}

The conduct of this study was facilitated by a Loughborough University Higher Education Innovation Fund sponsored Knowledge Exchange Program and received in-kind support from the transport company.

\section{Acknowledgments}

The authors would like to thank the Leicester Diabetes Centre Education team for their work on the design and delivery of the 6-hr education sessions in this study. The authors would also like to thank Dr Danielle Bodicoat for writing the output variable code used to generate the activity data presented in this current paper. 


\section{Author contribution}

This paper has been originally developed as part of VVM's doctoral thesis. VVM, SC, JK, TY conceived the study. MN and JK established the partnership between the university and the local company. VVM, NC and JK designed and implemented the data collection. HD and VJ designed and conducted the structured education session. SC, TY, JK and DS overviewed the data collection. CE processed the activPAL data. All authors contributed to writing and interpretation of the results. 
Manuscript (All Manuscript Text Pages, including, References

and Figure Legends - NO AUTHOR INFO)

\section{RUNNING TITLE: A Structured Health Intervention for Truckers - SHIFT \\ RUNNING TITLE: A Structured Health Intervention for Truckers - SHIFT}




\section{ABSTRACT}

Objective: To examine the effects of implementing a lifestyle health behaviour intervention on cardiovascular risk markers in a sample of lorry drivers.

Methods: 57 males participated in the pre-post evaluation of a multicomponent 12-week intervention.

Results: Favourable changes in several cardiovascular health indicators were observed, including fasting blood glucose $(-0.6 \mathrm{mmol} / \mathrm{I}), \mathrm{LDL}$-Cholesterol $(-0.7 \mathrm{mmol} / \mathrm{l})$, total cholesterol $(-0.7 \mathrm{mmol} / \mathrm{l})$, waist-hip ratio $(-0.10)$ and waist circumference $(-2.5 \mathrm{~cm}) \quad(p<.01)$. The proportion of participants with a $>10 \%$ risk of a cardiovascular event in the next 10 years reduced by $12 \%(p<.05)$. A $21 \%, 12 \%$ and $7.5 \%$ reduction in drivers with pre-diabetes $(p<.001)$, undiagnosed diabetes $(p<.05)$ and the metabolic syndrome $(p<.05)$, respectively, was observed.

Conclusion: This study highlights the feasibility of implementing a multicomponent health intervention within the transport setting and provides preliminary evidence of its beneficial effects on some markers of health.

Key words: lorry drivers, physical activity, sitting time, cardiovascular markers, health intervention, transport setting. 


\section{INTRODUCTION}

Long distance driving is recognised as an occupation that is detrimental to the health and well-being of employees. ${ }^{1}$ Long distance drivers are exposed to a multitude of risk factors including long and variable working hours, prolonged periods of sitting, limited time available for physical activity, lack of healthy food choices on the road and erratic schedules which contributes to psychological stress and sleep deprivation. ${ }^{2}$ These stressors have been linked with an increased risk of overweight and obesity, metabolic syndrome, diabetes, hypertension, heart disease, cancer, fatigue, stress, sleep disturbance, sleep deprivation and musculoskeletal disorders. ${ }^{3.4 .5}$ Consequently, US data suggest that male lorry drivers have a life expectancy 12 years lower than the national average of 75.1 years. ${ }^{6,7}$ Whilst no comparable data have been reported for UK lorry drivers, national statistics indicate that transport workers have among the lowest life expectancies compared to other professional groups. $^{8}$

Previous research has indicated that only a small proportion of lorry drivers appear to be physically active ( $8 \%$ to $26 \%)^{9}$ and it has been highlighted that lorry drivers accumulate 13 hours of sedentary behaviour (sitting with low energy expenditure) on workdays. ${ }^{10}$ This is worrying since evidence shows that physical inactivity and high levels of sedentary behaviour are linked to an increased risk of cardiovascular disease (CVD), cardiovascular mortality, all-cause mortality, diabetes, cancer incidence and cancer mortality. ${ }^{11,12}$ 
Despite this, a recent systematic review of health promotion interventions in lorry drivers concluded that lorry drivers are an underserved group in terms of health promotion efforts. ${ }^{13}$ To compound this, long distance drivers are also an ageing workforce, with the mean age of the UK driver population $\left(n=\sim 285,000\right.$ ) currently at 53 years. ${ }^{14}$ Whilst the small body of literature targeting lorry drivers' health behaviours has generally led to improvements in markers of health, most studies conducted to date have focused on improving health outcomes through weight loss and diet interventions, ${ }^{13,15}$ whilst limited research has targeted physical activity ${ }^{16}$ and no studies have targeted sedentary behaviour.

This study therefore aimed to assess the effectiveness of an intervention designed to increase physical activity and reduce sedentary time, on workdays and non-workdays, and increase fruit and vegetable intake in a sample of lorry drivers. A secondary aim of the study was to examine any preliminary effects of the intervention on lorry drivers' markers of cardiovascular health.

\section{METHODS}

\section{Study design and participants}

A pre-post study design was adopted to examine the impact of a multicomponent 12-week health intervention. This was implemented with a staggered design at a large UK-based transport company in the East Midlands, as part of an ongoing health and well-being programme of research undertaken in partnership with the company. ${ }^{2}$ The health intervention was promoted by the researchers at different events denoted as "lobbying 
time" at the lorry drivers' transport office across all shift patterns (morning 06:00 to 14:00; afternoon 14:00 to 22:00; and night $22: 00$ to $06: 00)$. Newsletters were also posted in individual staff pigeon holes. This promotion was conducted over a 2-month period preintervention, during which researchers engaged with the long distance heavy goods vehicle (HGV) drivers. Out of the 272 drivers working at the company, 136 (50\%) from across all shift patterns were randomly selected to be invited to take part in the study. Drivers were assigned a number, which was then selected using an automated randomiser (www.randomizer.org). All selected drivers were then sent an official invitation letter and participant information sheet. The health intervention, including the pre and post-health assessments, took place between March and September 2015. Participants without current CVD, haemophilia, and any blood-borne viruses were included in the study. Ethical approval was obtained from the local Ethical Advisory Committee and all participants provided written informed consent. 


\section{Measurements of health biomarkers}

During the baseline health assessments, participating drivers self-reported their age, ethnicity and average weekly working hours. Drivers were asked to complete a Health Screen Questionnaire, in which they recorded any medical problems and medication, average daily intake of fruit and vegetables, average weekly alcohol intake and smoking status (current smoker, ex-smoker, amount per week). Anxiety and depression were assessed using the Hospital Anxiety and Depression Scale (HADS). ${ }^{17}$ Scores between 8-10 were considered borderline and those scoring 11 or over were considered as clinical 'caseness' for anxiety or depression. ${ }^{17}$

Resting blood pressure and heart rate were measured using the validated Omron Intellisense M7 Upper Arm monitor (Omro Ltd, UK), following recommendations of the European Hypertension Society. ${ }^{18}$ Height was measured without shoes using a portable stadiometer (Seca 206, Oxford, UK). Waist circumference was assessed using an anthropometric tape at the midpoint between the upper edge of the iliac crest and the inferior border of the last palpable rib. Hip circumference was measured around the widest part of the buttocks, with the tape parallel to the floor. The waist-hip ratio was subsequently calculated. Body composition and weight were assessed using a Tanita BC-418 MA Segmental Body Composition Analyser (Tanita UK Ltd). BMI was calculated as $\mathrm{kg} / \mathrm{m}^{2}$. In addition a fasted ( $\geq 8 \mathrm{~h}$ ) capillary (finger-tip) blood sample was taken, after heating the hand for 5 minutes, for the analysis of blood glucose (FBG) and triglycerides (TGs) using the Accutrend $^{\circledR}$ Plus Complete System (Roche Diagnostics, Mannheim, Germany) and Highdensity lipoprotein Cholesterol (HDL-C) and Total-Cholesterol (TC) using the Cardiochek PA 
Blood Analyser (BHR Pharmaceuticals Ltd, Nuneaton, UK). Low-density lipoprotein Cholesterol (LDL-C) was obtained using Friedewald's formula. ${ }^{19}$

Metabolic syndrome was defined as central obesity (waist circumference; males $\geq 102 \mathrm{~cm}$; females $\geq 88 \mathrm{~cm}$ ) plus any two of the following risk factors: raised blood pressure (systolic $\geq 130$ or diastolic $\geq 85 \mathrm{mmHg})$, raised TG $(\geq 1.7 \mathrm{mmol} / \mathrm{l})$, reduced $\mathrm{HDL}-\mathrm{C}(<1.0 \mathrm{mmol} / \mathrm{I}$ in males; $1.3 \mathrm{mmol} / \mathrm{l}$ in females) and raised fasting plasma glucose $(\geq 5.6 \mathrm{mmol} / \mathrm{l}) .{ }^{20}$ Ten year CVD risk was calculated using the QRISK2 calculator (http://www.qrisk.org/). ${ }^{21}$ All measurements were repeated immediately following the 3-month intervention.

\section{The Intervention - A Structured Health Intervention for Truckers (SHIFT)}

The SHIFT intervention comprises a multicomponent design which aims for the drivers to become more active, less sedentary and to improve their diet. The following strategies were introduced under the "SHIFT Study umbrella":

Counselling one-to-one: straight after the baseline health assessments lorry drivers received their own results. Meaningful information about each biomarker (FBG, TC, TGs, HDL-C, LDLC, waist circumference, BMI, systolic and diastolic blood pressure) was provided for the drivers; thus, during this session participants had the opportunity to discuss with the researcher potential health changes related to diet or activity with the aim of improving those factors outside the healthy ranges. 
The SHIFT structured education programme: participants (organised in groups of 4 to 8 drivers at a time) received a 6-hour group-based structured education programme, which provided drivers with information about diet, physical activity, sedentary behaviour and general lifestyle including alcohol consumption and tobacco use, sleep and stress and how these can affect their health and their HGV licence. Additionally, self-monitoring and selfregulation of activity was promoted through the use of a pedometer. The education session was delivered on site in one of the company's meeting rooms and specifically designed to cover the driver's needs, based on qualitative information gathered previously. ${ }^{2}$ It was delivered by trained educators and was grounded in health behaviour change theories including Bandura's social cognitive model ${ }^{22}$ and Leventhal's common sense model. ${ }^{23}$ Informed by earlier qualitative research, ${ }^{2}$ the education session was adapted from the DESMOND programme, which has been used successfully throughout the NHS for diabetes management. ${ }^{24}$

Cab-workout: This workout was designed to help drivers increase their physical activity levels during their working hours. It is a combination of exercises using big muscle groups lasting for 20 minutes. Lorry drivers were provided with "cab-workout" equipment involving resistance bands, grip strength dynamometers, a peddle cycle and fitness ball, along with a booklet with examples of different exercises. The "cab-workout" was introduced during the education session and lorry drivers were advised to do the workout during their breaks and long waits whist stationary where they were unable to leave their vehicle such as at certain stops for unloading/loading, where walking was not permitted.

Health coaching: During the intervention, researchers developed the role of health coaches, which aimed to keep motivation levels high and encourage drivers to continue with their 
small changes to improve health outcomes. The health coach was developed to provide drivers with easy access to health knowledge about physical activity and diet and to promote different activities through the intervention period. Monthly "catch-ups" were organised with the drivers across all shift patterns, where issues related to physical activity and diet were discussed with the drivers. However, drivers could seek advice at any point of time throughout the intervention, as researchers were based at the transport office.

Step challenges: as participants were provided with pedometers at the education session to facilitate self-monitoring and self-regulation, step count challenges were organised on a monthly basis by the researchers. During these activities drivers were grouped in teams and competed against each other or against their own baseline data.

Healthy packed lunch scheme: this was set up in coordination with the canteen service of the transport company. Healthy lunches were provided for drivers on a pre-order basis; this was heavily subsidised and included a full meal with drink and dessert ( $f 1.90)$. This was provided as an alternative to service stations' fast food.

In addition to these strategies, lorry drivers were provided with free membership at the company's gym for the duration of the intervention plus 3 months after the intervention. The company also provided, to those who won the step count challenges, a free 2-week pass for the drivers' appointed person (e.g. relative) at their local gym. Moreover, those aiming to lose weight and with a $\mathrm{BMI}>26 \mathrm{~kg} / \mathrm{m}^{2}$ (the cut-point chosen by the company) were offered a slimming world voucher for a 12-week course, which provided them with access to weekly meetings and general advice on diet. 


\section{Measurement of sitting, standing and physical activity}

Sitting, standing and stepping time were measured objectively using an activPAL3 monitor, which has been shown to be a valid measure of time spent sitting/lying, standing and walking in adults. ${ }^{25}$ The activPAL3 is a small device, worn on the front of the right thigh, which uses accelerometer-derived information about thigh position and acceleration to determine body posture (i.e., sitting/lying and upright) and transitions between these postures, stepping, and stepping speed (cadence). ${ }^{26}$ The activPAL3 was waterproofed using a nitrile sleeve and attached to the leg using a waterproof hypoallergenic medical dressing (BSN Hypafix). This enabled participants to wear it continuously for 24 hours/day over seven days, following their health assessments. Participants were asked to complete a daily-log book where they recorded the time they went to bed and woke up on workdays and nonworkdays. Information about any non-wear time was also recorded.

Data from the activPAL were downloaded using activPAL Professional v.7.2.29 software (device firmware version 3.107) and processed using a validated automated algorithm in STATA (StataCorp. College Station, TX: StataCorp LP). This has been described in detail elsewhere ${ }^{27}$ but in brief the algorithm uses the activPAL event files to isolate waking hours from 'sleeping' (time in bed), prolonged non-wear periods and invalid data. A valid day was defined as a day with $<95 \%$ of time spent in any one behaviour (e.g., standing or sitting), $>500$ steps were accrued across the day and $\geq 10$ hours of waking hours data. Participants were required to have at least four valid days of data at baseline and follow-up to be included in the analysis. Following processing, data were visually checked using 'heatmaps' of activity and any data that looked like potential sleep that had not been 
removed by the algorithm were checked with the self-reported diary times and corrected if necessary. This happened on occasion due to waking sitting/lying bouts sometimes being longer than sitting/lying bouts during sleep in this particular population due to the nature of their employment. Output variables included average time spent sitting/lying, average time spent in sitting/lying bouts of 0-29minutes, 30-59 minutes, 60-119 minutes and $\geq 120$ minutes, standing, stepping, number of steps per day and average waking wear time. For each participant, stepping time was further classified into MVPA (by summing the minutes in which participants accumulated $>100$ steps/minute) ${ }^{28}$ and light activity (LPA, stepping time minus MVPA). Those accumulating $\leq 30$ minutes/day of MVPA were considered physically inactive. ${ }^{29}$ The sitting bout length at which $50 \%$ of sitting time was accumulated was calculated using accumulation curves (proportion of total sitting time (Y-axis) plotted against each bout of sitting time in increasing duration (X-axis)). ${ }^{30}$

\section{Statistical analysis}

Statistical analyses were conducted using SPSS v.22 (SPSS Inc., Chicago, IL, USA). All variables were checked for normality using the Shapiro-Wilk Test, which confirmed that data were normally distributed. Thus, parametric statistical tests were used throughout. Mean and standard deviation (SD) values were computed for all variables. Change in biomarkers including body measurements, blood pressure, blood markers and lifestyle behaviours (fruit and vegetable intake, alcohol consumption and tobacco smoked) were assessed using paired-sample t-tests. Change in activity data including average numbers of steps/day, average time spent in light intensity and moderate-to-vigorous intensity stepping/day, average time spent sitting/day and standing/day, average number of sitting bouts/day, and 
'usual' sitting bout duration during workdays and non-workdays was also assessed using paired-sample t-tests. Linear regression models were fitted to explore the relationship between changes in overall step counts per day, step counts on workdays, step counts on non-workdays and cardiovascular markers. These were adjusted to control for potential cofounding variables such as age, ethnicity, education levels, shift pattern, smoking, alcohol intake and fruit and vegetable consumption. The linear coefficient represents the association of substituting one unit overall of step counts per day ( 1 unit $=1000$ steps/day), step counts per workdays ( 1 unit $=1000$ steps/day), and step counts during non-workdays ( 1 unit $=1000$ steps/day). Changes in the percentage of drivers with pre-diabetes, undiagnosed diabetes, metabolic syndrome and with $>10 \%$ risk of a cardiovascular event in the next 10 years (QRISK2) between pre and post-intervention were assessed using paired sample t-tests. Differences between those who completed the intervention and those who did not were explored for the above-mentioned variables using independent sample t-tests.

\section{RESULTS}

Figure 1 presents the flow of participants through the study. Out of the 72 male drivers that agreed to take part in the intervention and attended the baseline health assessments, 15 did not attend the 3-month follow-up (mean (SD), age: 53.4(3.4) years; BMI: 29.9(2.4) $\mathrm{kg} / \mathrm{m}^{2}$ ). Therefore, 57 drivers (age: $49.5\left(9.1\right.$ ) years; BMI: $29.3(4.7) \mathrm{kg} / \mathrm{m}^{2}$ ) completed the pre-and-post health assessments. Those not completing the study had a significantly higher systolic and diastolic blood pressure (SBP: 11.5(2.6) mmHg; DBP: 9.9(2.4) mmHg; $\mathrm{p}<.001$ ), higher reported alcohol consumption (units of alcohol: 7.0(3.1); $p<0.05$ ) and smoked less cigarettes per week (cigarettes: 83.1(33.0), $\mathrm{p}<.05$ ) than those completing the study. Out of 
the 57 drivers, 43 (age: 50.5 (8.5) years; BMI: $28.4(3.9) \mathrm{kg} / \mathrm{m}^{2}$ ) provided valid activPAL data at both assessment time points (Table 1 displays participants' demographic and medical information; Table 2 displays participants' physiological health status information.).

Insert Figure 1 about here: Flow chart representing the lorry drivers' sample size and the uptake into the study

Out of 57 drivers, at baseline $88 \%$ were physically inactive, $84 \%$ were overweight or obese, $78 \%$ were pre-hypertensive or hypertensive (5\%), $26 \%$ had the metabolic syndrome, $29 \%$ had pre-diabetes, $12 \%$ had undiagnosed diabetes, $7.5 \%$ had diagnosed diabetes and $24 \%$ possessed $>10 \%$ risk of having a cardiovascular event in the next 10 years. Table 2 presents the changes in health assessment measures between baseline and 3-months follow-up. Overall, positive changes between the pre-and-post health assessments were found for waist circumference, waist-hip ratio, heart rate, FBG, LDL-C, TC, average fruit and vegetables consumed per day $(p<0.05$, Table 1 and 2$)$. These positive changes resulted in a $12 \%$ reduction in the proportion of drivers who possessed $>10 \%$ risk of having a cardiovascular event in the next 10 years (QRISK) $(p<.05)$. In addition, these positive changes resulted in a $21 \%$ reduction in drivers with pre-diabetes $(p<.001)$, a $12 \%$ reduction in drivers with undiagnosed diabetes $(p<.05)$ and a $7.5 \%$ reduction in drivers with the metabolic syndrome $(p<.05)$. 
Tables 3 and 4 report the changes in activity variables between baseline and 3-months follow up. Compared to baseline, at 3-month follow-up lorry drivers spent more time sitting in the shorter bout duration of 0-29 minutes (hours/day) $(p<.05)$ (Table 3 and 4). No significant differences in daily step counts were observed between baseline and follow-up.

Insert Tables 3 and 4 about here

Table 5 presents the linear regression models exploring the association between overall step counts per day, step counts during workdays and non-workdays and FBG, HDL-C, LDL-C, TGs, TC and TG-HDL ratio. A one unit increase in step counts during workdays was positively associated with changes in HDL-C ( $r=.04, p=.034)$.

Insert Table 5 about here

Figure 2 shows that on average (mean (SD)) lorry drivers accumulated approximately half of their daily sitting time in bouts lasting $46.5(0.5)$ minutes at baseline, whilst this significantly reduced at 3-months follow-up to $42.8(0.3)$ minutes $(p<0.001)$.

Insert Figure 2 about here 


\section{DISCUSSION}

This study examined the effects of a multicomponent intervention on physical activity, sedentary behaviour and markers of health, in a sample of lorry drivers. This study has confirmed that it is feasible to deliver this intervention in a sample of lorry drivers, and this holds promise given favourable changes were observed in a number of measures. The findings suggest that this novel intervention induced positive changes in the participants sitting patterns, whose average sitting bout duration was slightly shorter at follow-up. In addition, favourable changes were observed in waist circumference, waist-hip ratio, FBG, LDL-C, TC and reported daily fruit and vegetable intakes. The significance of these results is of importance considering the small scale of this study, hence not powered to detect significant changes. Therefore, the non-significant increase in overall daily steps observed in this study holds promise for further testing of this intervention in an appropriately powered study.

\section{How this study fits in the literature}

Lorry drivers' everyday activities and working practices are constructed within a primarily economic rationality, which emphasises a need for continual productivity. ${ }^{2}$ This is evident by the working environment, culture and job demands (sustained long irregular hours, enforced sedentarism, high stress) lorry drivers face on daily basis within the transport industry. ${ }^{2}$ These constrain the enactment of healthy lifestyle behaviours, resulting in high levels of obesity, metabolic syndrome and mental ill health (stress, depression, anxiety). ${ }^{31,32}$ Additionally, the driver population in the UK $(n=285,000)$ is an ageing workforce (mean age: 
53 years), ${ }^{33}$ and collectively, these factors identify an underserved, high risk population. Limited health interventions have been implemented in this occupational group to date and of these most interventions have focused on weight loss with established targets independent of the participant's baseline assessments. ${ }^{13,15,34}$ Thiese and colleagues $(2015)^{15}$ reported the highest weight loss in their study $(-5.1 \mathrm{~kg})$, in which they aimed to test the feasibility of a 12-week intervention for long-haul truck drivers $(n=12)$. Similar to the present study, this intervention provided drivers with weekly health coaching and driver specific materials focused on healthy eating tools, exercise equipment and tips for a healthy lifestyle. Contrary to the present study, Thiese and colleagues ${ }^{15}$ set up a target of $10 \%$ weight loss for every driver at baseline, which only 4 drivers achieved. This conflicts with the SMART goal theory ${ }^{35}$ in which the present study was based, which promotes realistic and achievable goals to avoid disengagement and the feeling of failure.

\section{Development and design of the SHIFT Intervention}

The isolated nature of lorry driving and the limited opportunities for drivers to fulfil a healthy lifestyle means that drivers must perform most aspects of any health intervention without assistance or very limited social reinforcement. Thus, increasing drivers understanding about their own health behaviours, providing them with self-monitoring tools such as pedometers and facilitating health coaching sessions on a regular basis is of high importance. This intervention is a continuation of previous quantitative and qualitative research ${ }^{2,10}$ conducted in a large sample of UK lorry drivers from the same company. During these phases, lorry drivers were involved in the development and design of the present intervention through public involvement events and by participating in qualitative research, 
which informed the intervention. This is the first study to involve the company's management team to facilitate drivers with opportunities conducive of healthier behaviours such as free membership to the gym on site, healthy pack lunches and paid time off for the drivers to attend their health assessments and the education session. In addition, this intervention is the first delivered at a transport company that has been informed by the drivers themselves ${ }^{2}$ using evidence-based theories to promote health behaviour change. ${ }^{22,23,24}$ It is likely that this approach had a positive effect on the retention levels at the 3-month follow up, as $79 \%$ of the sample attended the 3-month follow-up health assessments. This retention rate was higher than that observed in other studies, which did not reach $50 \%$ of the sample. ${ }^{13,16}$

\section{Clinically meaningful cardiovascular changes}

Similar to the findings in other countries, ${ }^{16,36}$ these UK drivers presented with a wide range of chronic disease risk factors such as high levels of sitting time, inactivity, unhealthy cardiovascular profiles, overweight and obesity at baseline. Participants in this study significantly reduced their waist circumference and waist-hip ratio, which have been described as a superior measure of CVD risk compared to $\mathrm{BMI} .{ }^{37}$ De Koning and colleagues $(2007)^{37}$ in their meta-analysis reported that reductions of $1 \mathrm{~cm}$ around the waist and a 0.01 unit decrease in waist-hip ratio were associated with a 2 and $5 \%$ lower risk of cardiovascular events, respectively. Participants from this intervention reduced their waist circumference by $2.5 \mathrm{~cm}$ and their waist-hip ratio by 0.01 units, which has been defined as clinically meaningful. ${ }^{37}$ Similar results were only observed by Olsen et al (2009), ${ }^{34}$ in which 
intervention drivers presented a $3.5 \mathrm{~cm}$ waist circumference reduction at the end of the 6 month intervention.

Limited interventions have focused on improving lorry drivers' lipid profile ${ }^{13}$ and of the research available this has been mostly focused on reducing total cholesterol. ${ }^{37}$ Positive changes in FBG, LDL-C and TC were achieved across the whole sample. These changes had further implications in validated clinical indexes such as the fasting blood glucose classification, ${ }^{38}$ the Metabolic Syndrome ${ }^{20}$ or the QRISK2. ${ }^{21}$ Out of the $41 \%$ of drivers that initially were classified as pre-diabetic or had undiagnosed diabetes, only $9 \%$ were clustered as pre-diabetic at 3 months. Out of the $23 \%$ of drivers that initially had the Metabolic Syndrome, 15\% presented with the Metabolic Syndrome at 3 months. The NICE guidelines $(2014)^{39}$ recommend prioritising people for a full risk assessment if their estimated 10-year risk of CVD is $10 \%$ or more. $24 \%$ of the sample displayed $\geq 10 \%$ risk of a cardiovascular event at baseline, yet this was significantly reduced to $12 \%$ at 3 months. This is of significant importance considering the high prevalence of cardiovascular events seen in lorry drivers compared to the general population. ${ }^{6,15}$

\section{Changes in physical activity and sedentary behaviours}

Whilst the protective health effects of MVPA are well known,${ }^{41}$ complying with the physical activity guidelines ${ }^{29}$ seems a bridge difficult to cross amongst highly sedentary populations. ${ }^{42}$ The feasibility of substituting sedentary time by equal amounts of MVPA amongst subjects with the metabolic syndrome, type 2 diabetes, overweight or obesity has 
been questioned previously; $;^{43}$ as these individuals seem to negatively respond to bouts of high-intensity exercise. ${ }^{44}$ Drivers from this sample were encouraged to increase their physical activity levels through increasing their step counts based on their own baseline data and their daily routine as a strategy to improve their health outcomes. Overall, physical activity did not change significantly during workdays and non-workdays at 3-months followup, which could be due to the time of the year in which these assessments where conducted. These coincided with one of the company's busiest months, in which drivers were required to be out on the road for several days at a time. Nonetheless, linear regression models indicate that positive changes in HDL-C were associated with increases in step counts during workdays. Indeed, $81 \%$ of this sample increased their step counts during workdays and nonworkdays at 3 months.

The present results also indicate that lorry drivers modified their sitting patterns slightly, reducing significantly the duration of their average sitting bout by 4 minutes at 3-months follow-up. Although this reduction is unlikely to have sufficient impact on drivers' health, it is of significant importance considering lorry drivers are 'compulsory sedentary workers' and the time of the year in which the follow-up assessments were collected. These results are relevant for future interventions, particularly for overweight and obese individuals, for which increasing their step counts and reducing their sitting time might be a more feasible strategy initially rather than accruing increases in MVPA. 


\section{Strengths, limitations and future research}

Given the nature of the present study, limitations of this work include the small sample, the lack of a control group and the lack of a longer-term follow-up assessment. Our data are also restricted to lorry drivers recruited from a single workplace within the East Midlands (UK). Despite these limitations, this study is the first of its kind to assess a multicomponent intervention targeting physical activity and sedentary behaviour in a sample of lorry drivers. This is also the first study to use a robust measure of activity and sitting.

Based on the concept of this intervention, it is likely the core design could be applicable to other occupational groups from the transport sector (e.g. bus drivers, taxi drivers, train drivers), however, the key success of this intervention was its bespoke design to suit the particular needs of this sample of lorry drivers. Future research should build on this work by examining the effectiveness, and cost-effectiveness, of this intervention using a robust cluster randomised controlled trial, using lorry drivers from multiple sites. In addition, future research should investigate modifying the intervention to tailor it to other transport-based workers.

\section{Conclusion}

This paper highlights the feasibility of implementing a multicomponent health intervention within the transport setting and provides preliminary evidence of beneficial effects of the intervention on some markers of drivers' health. The multicomponent design provides lorry drivers with a variety of opportunities for them to engage in health behaviours based on their own priorities and goals. Future research should test this study in a larger scale trial design. 


\section{REFERENCES}

1. U.S. Bureau of Labor Statistics, Workplace Safety and Health, 2010, www.bls.gov/ opub/mlr/2010/11/art3full.pdf (accessed October 9, 2012).

2. Caddick N, Varela-Mato V, Nimmo MA, et al. Understanding the health of lorry drivers in context: A critical discourse analysis. Health (London) 2017;21:38-56.

3. Robinson CF, Burnett CA. Truck drivers and heart disease in the united states, 19791990. Am J Ind Med 2005;47:113-9.

4. Transportation Research Board. (2007). The Domain of Truck and Bus Safety Research. Washington, DC. http://www.trb.org/Main/Home.aspx (Accessed 08.04.016)

5. Apostolopoulos Y, Sonmez S, Shattell MM, et al. Health survey of U.S. long-haul truck drivers: Work environment, physical health, and healthcare access. Work 2013;46:113-23.

6. Heron MP, Hoyert DL, Murphy SL, et al. Deaths: Final data for 2006. [2009] Retrieved from www.cdc.gov/nchs/data/nvsr/nvsr57/nvsr57 14.pdf

7. Saltzman GM, \& Belzer MH (2007). Truck driver occupational safety and health: 2003 Conference report and selective literature review (DHHS [NIOSH] Publication No. 2007-120). Retrieved from www.cdc.gov/niosh/docs/2007-120/pdfs/2007-120.pdf

8. ONS (2011). Statistical Bulletin: Trends in life expectancy by the National Statistics Socio-economic Classification 1982-2006. Available at file://C:/Users/admin/Downloads/trendsinlifeexpectanc_tcm77-238656.pdf [Accessed 14/08/2015]. 
9. Sieber WK, Robinson CF, Birdsey J, et al. Obesity and other risk factors: The national survey of U.S. long-haul truck driver health and injury. Am J Ind Med 2014;57:615-26.

10. Varela-Mato $V$, Yates $T$, Stensel $D$, et al. Time spent sitting during and outside working hours in bus drivers: A pilot study. Preventive Medicine Reports 2015; Volume 3:36-9.

11. Lee IM, Shiroma EJ, Lobelo F, et al. Effect of physical inactivity on major noncommunicable diseases worldwide: An analysis of burden of disease and life expectancy. Lancet 2012;380:219-29.

12. de Rezende LF, Rodrigues Lopes M, Rey-Lopez JP, et al. Sedentary behavior and health outcomes: An overview of systematic reviews. PLoS One 2014;9:e105620.

13. Ng MK, Yousuf B, Bigelow PL, et al. Effectiveness of health promotion programmes for truck drivers: A systematic review. Health Education Journal. 2015 May;74(3):270-86.

14. The Freight Transport Association. Logistics Report 2015. Freight Transport Association Limited, 2015.

15. Puhkala Gilson ND, Pavey TG, Vandelanotte C, et al. Chronic disease risks and use of a smartphone application during a physical activity and dietary intervention in australian truck drivers. Aust N Z J Public Health 2015.

16. Zigmond AS, Snaith RP. The hospital anxiety and depression scale. Acta Psychiatr Scand 1983;67:361-70.

17. Parati G, Stergiou G, O'Brien E, et al. European society of hypertension practice guidelines for ambulatory blood pressure monitoring. J Hypertens 2014;32:1359-66. 
18. Friedewald WT, Levy RI, Fredrickson DS. Estimation of the concentration of lowdensity lipoprotein cholesterol in plasma, without use of the preparative ultracentrifuge. Clin Chem 1972;18:499-502.

19. Alberti KG, Eckel RH, Grundy SM, et al. Harmonizing the metabolic syndrome: A joint interim statement of the international diabetes federation task force on epidemiology and prevention; national heart, lung, and blood institute; american heart association; world heart federation; international atherosclerosis society; and international association for the study of obesity. Circulation 2009;120:1640-5.

20. Hippisley-Cox J, Coupland C, Vinogradova Y, et al. Predicting cardiovascular risk in england and wales: Prospective derivation and validation of QRISK2. BMJ 2008;336:1475-82.

21. Bandura A. Social foundations of thought and action: A social cognitive theory.: Prentice-Hall, Inc; 1986.

22. Leventhal H, Meyer D, Nerenz D. The common sense representation of illness danger. Contributions to medical psychology 1980;2:7-30.

23. Yates T, Davies MJ, Henson J, et al. Walking away from type 2 diabetes: Trial protocol of a cluster randomised controlled trial evaluating a structured education programme in those at high risk of developing type 2 diabetes. BMC family practice 2012;13:1.

24. Kozey-Keadle S, Libertine A, Lyden K, et al. Validation of wearable monitors for assessing sedentary behavior. Med Sci Sports Exerc 2011;43:1561-7.

25. Edwardson $\mathrm{CL}$, Winkler EA, Bodicoat $\mathrm{DH}$, et al. Considerations when using the activPAL monitor in field-based research with adult populations. Journal of Sport and Health Science 2016. 
26. Winkler EA, Bodicoat $\mathrm{DH}$, Healy $\mathrm{GN}$, et al. Identifying adults' valid waking wear time by automated estimation in activPAL data collected with a $24 \mathrm{~h}$ wear protocol. Physiol Meas 2016;37:1653.

27. Rowe DA, Welk GJ, Heil DP, et al. Stride rate recommendations for moderateintensity walking. Med Sci Sports Exerc 2011;43:312-8.

28. Department of Health. Physical activity guidelines for adults aged 19-64 years old. 2015. https://www.gov.uk/government/publications/uk-physical-activity-guidelines

29. Chastin SF, Granat MH. Methods for objective measure, quantification and analysis of sedentary behaviour and inactivity. Gait Posture 2010;31:82-6.

30. Wong WC, Tam SM, Leung PW. Cross-border truck drivers in Hong Kong: their psychological health, sexual dysfunctions and sexual risk behaviors. J Travel Med 2007;14(1):20-30

31. Caddick N, Varela-Mato V, Nimmo MA et al. Understanding the health of lorry drivers in context: A critical discourse analysis. Health 2017;21(1):38-56.

32. Bigert C, Gustavsson P, Hallqvist J et al. Myocardial infarction among professional drivers. Epidemiology 2003;14(3):333-9.

33. Olson R, Anger WK, Elliot DL, et al. A new health promotion model for lone workers: Results of the safety \& health involvement for truckers (SHIFT) pilot study. J Occup Environ Med 2009;51:1233-46.

34. Doran GT. There'sa SMART way to write management's goals and objectives. Manage Rev 1981;70:35-6.

35. Sangaleti CT, Trincaus MR, Baratieri T, et al. Prevalence of cardiovascular risk factors among truck drivers in the south of brazil. BMC Public Health 2014;14:1. 
36. de Koning L, Merchant AT, Pogue J, et al. Waist circumference and waist-to-hip ratio as predictors of cardiovascular events: Meta-regression analysis of prospective studies. Eur Heart J 2007;28:850-6.

37. Holmes SM, Power ML, Walter CK. A motor carrier wellness program: Development and testing. Transportation Journal 1996:33-48.

38. Diabetes UK. Blood sugar level ranges. 2016. http://www.diabetes.co.uk/diabetes_care/blood-sugar-level-ranges.html (accessed 22.09.2016)

39. National Institute for Health and Care Excelence (NICE). Cardiovascular disease: risk assessment and reduction, including lipid modification. 2014. (accessed 13.01.2017)

40. Warburton DE, Nicol CW, Bredin SS. Health benefits of physical activity: The evidence. CMAJ 2006;174:801-9.

41. Tucker JM, Welk GJ, Beyler NK. Physical activity in US adults: Compliance with the physical activity guidelines for americans. Am J Prev Med 2011;40:454-61.

42. Duvivier BM, Schaper NC, Bremers MA, et al. Minimal intensity physical activity (standing and walking) of longer duration improves insulin action and plasma lipids more than shorter periods of moderate to vigorous exercise (cycling) in sedentary subjects when energy expenditure is comparable. PloS one 2013;8:e55542.

43. Ekkekakis P, Lind E. Exercise does not feel the same when you are overweight: The impact of self-selected and imposed intensity on affect and exertion. Int J Obes 2006;30:652-60. 


\section{LIST OF FIGURE CAPTATIONS}

Figure 1. Flow chart representing the lorry drivers' sample size and the uptake into the study

Figure 2. Percentage of sitting time in relation to bout duration across the whole sample at baseline and 3 months follow up $(n=43)$.

Table 1. Participants' demographic and medical information. Mean (SD) or percentage pre and post test values are shown for the sample of UK lorry drivers completing the study $(\mathrm{N}=57)$.

Table 2. Participants' physiological health status information. Mean (SD) or percentage pre and post test values are shown for the sample of UK lorry drivers completing the study $(\mathrm{N}=57)$.

Table 3. Mean (SD) or percentage pre and post test values are shown for sitting time, sitting bouts and physical activity data for the sample of UK lorry drivers completing the study $(\mathrm{N}=43)$.

Table 4. Mean (SD) or percentage pre and post test values are shown for sitting time, sitting bouts and physical activity data for workdays and non-workdays for the sample of UK lorry drivers completing the study $(\mathrm{N}=43)$.

Table 5. Linear regression model exploring the changes in FBG, HDL-C, LDL-C, TGs, TC and TG-HDL ratio in association with overall step counts, step counts during workdays 
and non-workdays. 


\section{Baseline}

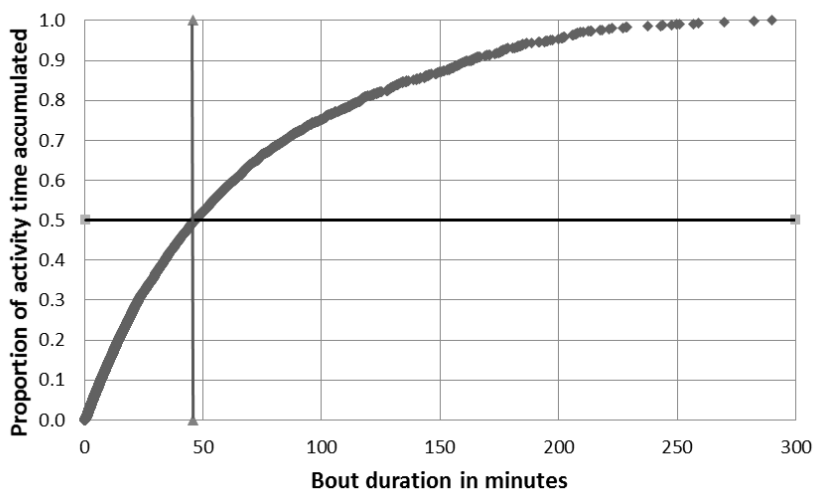

3 month follow-up

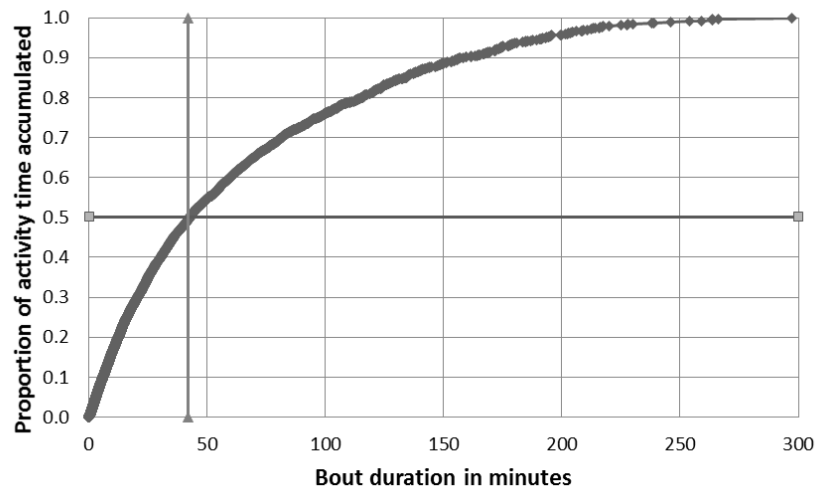

Figure 2. Percentage of sitting time in relation to bout duration across the whole sample at baseline and 3 month follow up $(n=43)$. 


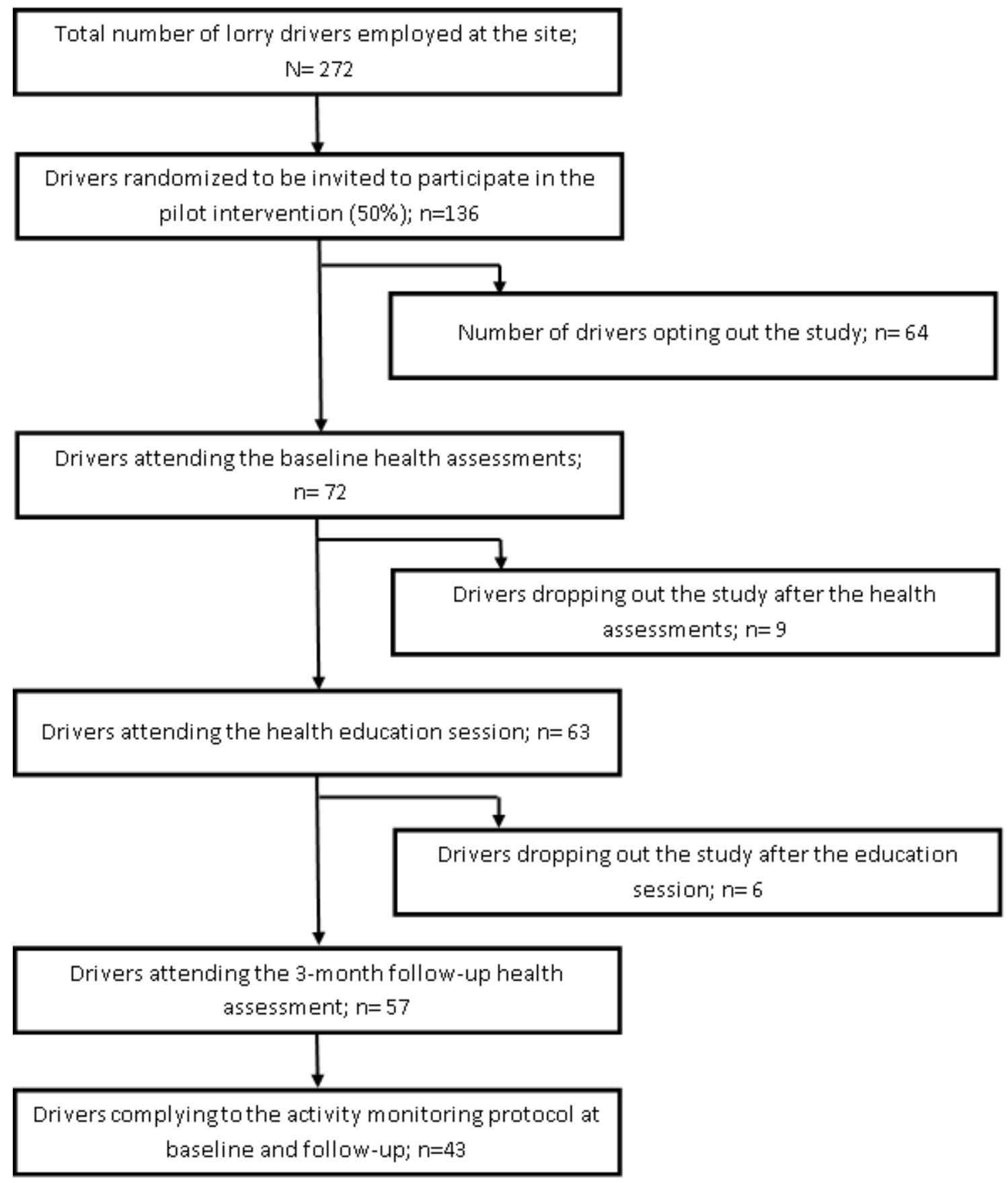

Figure 1. Flow chart representing the lorry drivers' sample size and the uptake on the study. 
Table 1. Participants' demographic and medical information. Mean (SD) or percentage pre-and-posttest values are shown for the sample of UK lorry drivers completing the study ( $N=57)$.

\begin{tabular}{|c|c|c|c|c|}
\hline & $\mathrm{N}$ & $\begin{array}{c}\text { Baseline } \\
\text { (Mean } \\
(\mathrm{SD}) \text { or number } \\
(\%))\end{array}$ & $\begin{array}{l}\text { 3-month follow-up } \\
\text { (Mean } \\
\text { (SD) or number (\%)) }\end{array}$ & $P$ value \\
\hline Age (yrs.) & 57 & $49.5(5)$ & & \\
\hline Marital status & 57 & & & \\
\hline Single & & $7.0 \%$ & & \\
\hline Married or partnered & & $77.1 \%$ & & \\
\hline Separated or divorced & & $15.8 \%$ & & \\
\hline Ethnicity & 57 & & & \\
\hline White European & & $95.3 \%$ & & \\
\hline Asian/Asian British & & $4.7 \%$ & & \\
\hline Highest level of Education & 57 & & & \\
\hline GCSES & & $83.3 \%$ & & \\
\hline A-levels & & $8.3 \%$ & & \\
\hline Other & & $8.4 \%$ & & \\
\hline Medical Information & 57 & & & .105 \\
\hline $\begin{array}{l}\text { CV-related medication (BP, } \\
\text { Thrombosis, Cholesterol) }\end{array}$ & & $17.4 \%$ & $9.5 \%$ & \\
\hline Musculoskeletal issues & & $15.5 \%$ & $19.0 \%$ & \\
\hline Asthma & & $8.7 \%$ & $7.1 \%$ & \\
\hline Other health conditions & & $17.4 \%$ & $7.1 \%$ & \\
\hline Anxiety (borderline/abnormal) & 57 & $8.9 \%$ & $4.3 \%$ & .031 \\
\hline Depression (borderline/abnormal) & 57 & $2.2 \%$ & $5.7 \%$ & .027 \\
\hline \multicolumn{5}{|l|}{ Lifestyle behaviours } \\
\hline Avg. fruit and vegetables /day & 57 & $4.6(3.0)$ & $5.4(2.5)$ & .014 \\
\hline Alcohol units/week & 40 & $13.1(12.1)$ & $15.3(15.10)$ & .130 \\
\hline Cigarettes/week & 15 & $149.4(79.2)$ & $148.4(87.59)$ & .915 \\
\hline
\end{tabular}

Abbreviations: CV-related medication, cardiovascular-related medication; 
Table 2. Participants' physiological health status information. Mean (SD) or percentage pre-and-posttest values are shown for the sample of UK lorry drivers completing the study ( $N=57)$.

\section{Body Composition}

\% Body fat

Waist circumference $(\mathrm{cm})$

Waist-Hip ratio $(\mathrm{cm})$

BMI $\left(\mathrm{kg} / \mathrm{m}^{2}\right)$

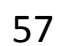

57

57

57

57

57

57

Heart rate (beats/min)

Blood Markers (mmol/l)

57

25.5(5.4)

104.3(12.5)

1.0(0.1)

29.3(4.7)

129.5(11.9)

82.2(8.7)

65.5(10.6)

5.3(1.0)

1.4(0.4)

3.2(1.3)

2.1(1.2)

5.1(1.4)

1.7(1.2)
25.3(5.7)

101.9(12.7)

$0.9(0.1)$

29.3(4.9)

128.3(12.5)

80.4(10.1)

63.3(9.2)

4.8(0.9)

$1.4(0.4)$

2.4(0.7)

2.3(1.4)

$4.2(0.8)$

1.8(1.3)
.904

$<.01$

$<.001$

.954

TG-HDL ratio

Abbreviations: CV-related medication, cardiovascular-related medication; BMI, Body Mass Index; FBG, Fasting Blood Glucose; HDL, High-density Lipoprotein Cholesterol; LDL, Low-density Lipoprotein Cholesterol; TG's, Triglycerides; TC, Total-Cholesterol. 
Table 3. Mean (SD) or percentage pre-and-post-test values are shown for sitting time, sitting bouts and physical activity data for the sample of UK lorry drivers completing the study $(\mathrm{N}=43)$.

$\begin{array}{ccc}\text { Baseline } & \text { 3-month follow-up } & \\ \text { (Mean } & \text { (Mean } & \text { P value }\end{array}$

(SD) or umber $\quad$ (SD) or number

(\%))

(\%))

\begin{tabular}{lccc}
\hline Overall & & & \\
Sitting time (hours/day) & $10.4(1.4)$ & $10.8(1.6)$ & .148 \\
Sitting bouts & & & \\
$\quad$ 0-29minutes (hours/day) & $4.1(1.0)$ & $4.6(0.9)$ & .015 \\
30-59 minutes (hours/day) & $2.3(0.7)$ & $2.2(0.7)$ & .489 \\
60-119 minutes (hours/day) & $2.2(1.0)$ & $2.2(0.9)$ & .995 \\
$\quad 120$ minutes (hours/day) & $1.7(1.0)$ & $1.7(0.9)$ & .838 \\
Standing (hours/day) & $3.8(1.1)$ & $3.8(0.9)$ & 1.000 \\
Light stepping (hours/day) & $0.9(0.3)$ & $0.9(0.3)$ & .631 \\
MV Stepping (hours/day) & $0.1(0.1)$ & $0.1(0.1)$ & .993 \\
Total steps per day & $8786.1(2919.0)$ & $9541.3(3183.7)$ & .093 \\
\hline
\end{tabular}

Abbreviations: MV Stepping, Moderate to Vigorous stepping, 
Table 4. Mean (SD) or percentage pre and-post-test values are shown for sitting time, sitting bouts and physical activity data for workdays and non-workdays for the sample of UK lorry drivers completing the study $(\mathrm{N}=43)$.

\begin{tabular}{lccc}
\hline Workdays & & & \\
Sitting time (hours/day) & $12.1(1.6)$ & $12.4(2.2)$ & .490 \\
Sitting bouts & & & \\
0-29minutes (hours/day) & $4.0(1.3)$ & $4.6(1.5)$ & .031 \\
30-59 minutes (hours/day) & $2.5(0.9)$ & $2.5(1.2)$ & .670 \\
60-119 minutes (hours/day) & $2.9(1.4)$ & $2.8(1.1)$ & .527 \\
$\quad \geq 120$ minutes (hours/day) & $2.6(1.8)$ & $2.5(1.4)$ & .342 \\
Standing (hours/day) & $3.2(0.9)$ & $3.2(1.2)$ & .994 \\
Light stepping (hours/day) & $1.2(0.2)$ & $1.2(0.2)$ & .817 \\
MV Stepping (hours/day) & $0.1(0.1)$ & $0.1(0.1)$ & .938 \\
Total steps per day & $8114.0(2579.5)$ & $8748.1(2795.7)$ & .086 \\
Non-Workdays & & & .391 \\
Sitting time (hours/day) & $8.7(2.1)$ & $9.2(2.2)$ & .204 \\
Sitting bouts & & & .256 \\
$\quad$ 0-29minutes (hours/day) & & & .777 \\
$\quad 30-59$ minutes (hours/day) & $4.6(0.9)$ & $4.3(1.3)$ & .177 \\
60-119 minutes (hours/day) & $2.2(1.1)$ & $2.0(0.8)$ & .928 \\
$\quad \geq 120$ minutes (hours/day) & $1.7(1.5)$ & $1.6(1.1)$ & .524 \\
Standing (hours/day) & $0.6(1.1)$ & $0.9(1.3)$ & .972 \\
Light stepping (hours/day) & $4.3(1.5)$ & $4.3(1.7)$ & .252 \\
MV Stepping (hours/day) & $1.4(0.5)$ & $1.3(0.4)$ & $0.1(0.1)$ \\
Total steps per day & $0.1(0.1)$ & $10155.8(4454.7)$ & \\
\hline Abbreviations: MV Stepping,Moderate & $9291.3(3966.6)$ & \\
\hline
\end{tabular}

Abbreviations: MV Stepping, Moderate to Vigorous stepping, 
Table 5. Linear regression model exploring the changes on FBG, HDL-C, LDL-C, TGs, TC and TG-HDL ratio in association overall step counts, step counts during workdays and non-workdays.

\begin{tabular}{lccccccccccccc}
\hline & $\begin{array}{c}\mathrm{FBG} \\
\mathrm{B}(95 \% \mathrm{Cl})\end{array}$ & $\begin{array}{c}\mathrm{p} \\
\text { value }\end{array}$ & $\begin{array}{c}\mathrm{HDL}-\mathrm{C}(95 \% \mathrm{Cl}) \\
\mathrm{B}(\mathrm{p})\end{array}$ & $\begin{array}{c}\mathrm{LDL}-\mathrm{C} \\
\text { value }\end{array}$ & $\begin{array}{c}\mathrm{p}(95 \% \mathrm{Cl}) \\
\text { value }\end{array}$ & $\begin{array}{c}\mathrm{TGs} \\
\mathrm{B}(95 \% \mathrm{Cl})\end{array}$ & $\begin{array}{c}\mathrm{P} \\
\text { value }\end{array}$ & $\begin{array}{c}\mathrm{TC} \\
\mathrm{B}(95 \% \mathrm{Cl})\end{array}$ & $\begin{array}{c}\mathrm{P} \\
\text { value }\end{array}$ & $\begin{array}{c}\mathrm{TG}-\mathrm{HDL} \text { ratio } \\
\mathrm{B}(95 \% \mathrm{Cl})\end{array}$ & $\begin{array}{c}\mathrm{p} \\
\text { value }\end{array}$ \\
\hline $\begin{array}{l}\text { Overall steps } \\
\text { per day }\end{array}$ & $-.02(-.16, .11)$ & .744 & $.02(-.01, .06)$ & .509 & $-.14(-.08, .05)$ & .679 & $-.08(-.21, .06)$ & .250 & $-.00(-.07, .06)$ & .879 & $-.10(-.25, .04)$ & .159 \\
$\begin{array}{l}\text { Workday steps } \\
\text { per day }\end{array}$ & $-.03(-.19, .13)$ & .720 & $.04(.00, .09)$ & .034 & $-.01(-.09, .08)$ & .822 & $-.11(-.28, .06)$ & .191 & $-.01(-.07, .10)$ & .191 & $-.14(-.31, .03)$ & .105 \\
$\begin{array}{l}\text { Non-workday } \\
\text { steps per day }\end{array}$ & $-.01(-.01, .09)$ & .791 & $-.01(-.02, .04)$ & .473 & $-.01(-.06, .04)$ & .742 & $-.04(-.15, .06)$ & .396 & $-.00(-.05, .04)$ & .762 & $-.06(-.17, .05)$ & .298 \\
\hline
\end{tabular}

Abbreviations: FBG, fasting blood glucose, HDL-C, high-density lipoprotein cholesterol, LDL-C, low-density lipoprotein cholesterol, TGs, triglycerides, TC, total cholesterol, TG-HDL ratio, triglycerides-high-density lipoprotein cholesterol. 


\section{CLINICAL SIGNIFICANCE}

- Clinically meaningful changes were observed in waist-circumference, waist-hip ratio, fasting blood glucose, LDL cholesterol and Total cholesterol at 3-month follow-up. These led to meaningful reduction of drivers with a $>10 \%$ risk of a cardiovascular event in the next 10 years, and in drivers with pre-diabetes, undiagnosed diabetes and metabolic syndrome. 